$79-0386$

NASA-TM-7901619790006979

NASA Technical Memorandum 79016

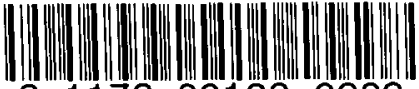

31176001330209

SPACE ENVIRONMENTAL INTERACTIONS

WITH SPACECRAFT SURFACES

N. John Stevens

Lewis Research Center

Cleveland, Ohio

TECHNICAL PAPER to be presented at the Seventeenth Aerospace Sciences Meeting sponsored by the American Institute of Aeronautics and Astronautics

New Orleans, Louisiana, January 15-17, 1979 


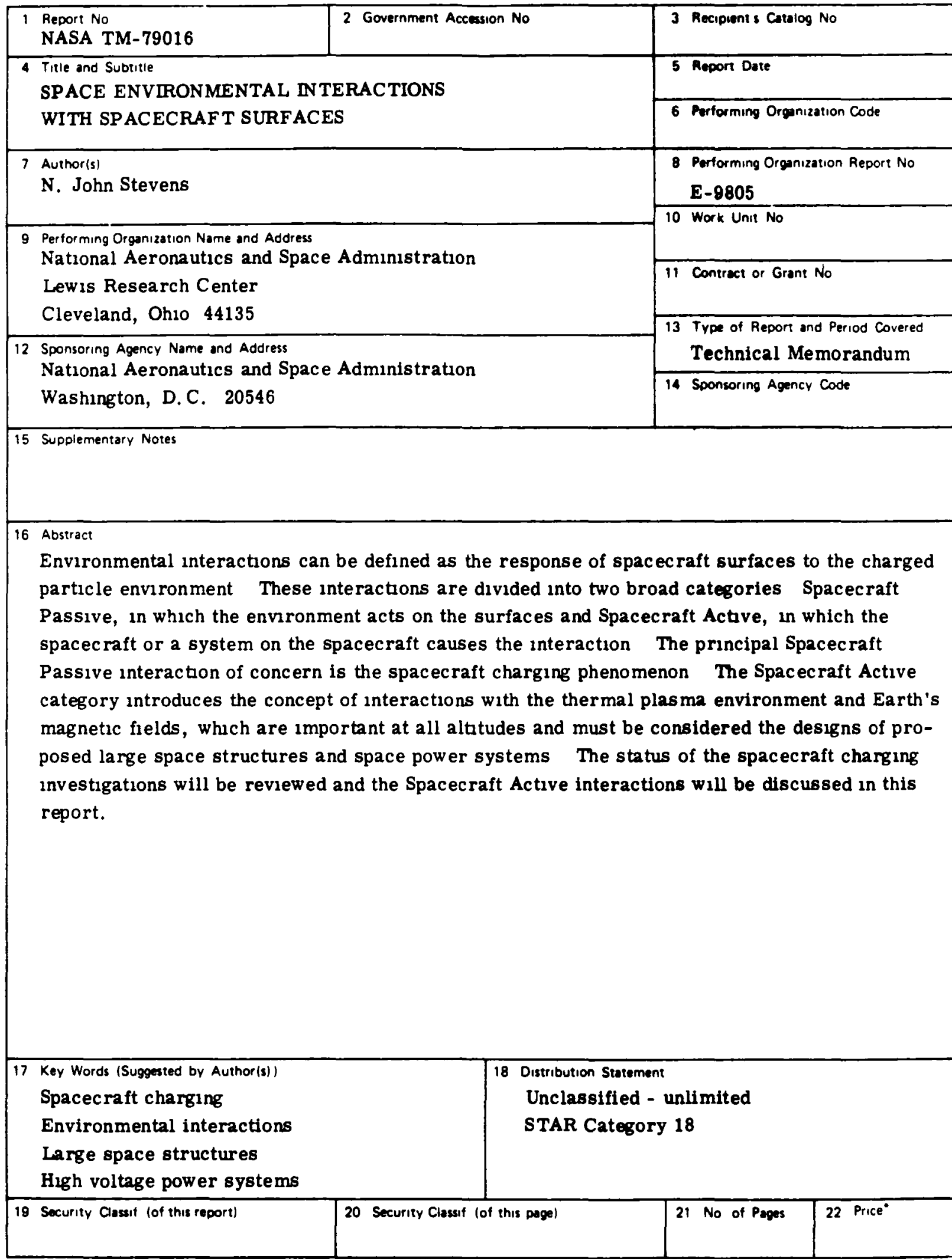

*For sale by the National Technical Information Service Springfield Virginı 22161 


\section{SPACE ENVIRONMENTAL INTERACTIONS WITH SPACECRAFT SURFACES}

by N. John Stevens

National Aeronautics and Space Administration

Lewis Research Center

Cleveland, Ohio 441.35

\section{ABSTRACT}

Environmental interactions can be defined as the response of spacecraft surfaces to the charged-particle environment. These interactions are divided into two broad categories: Spacecraft Passive, in which the environment acts on the surfaces and Spacecraft Active, in which the spacecraft or a system on the spacecraft causes the interaction. The principal Spacecraft Passive interaction of concern is the spacecraft charging phenomenon. The Spacecraft Active category introduces the concept of interactions with the thermal plasma environment and Earth's magnetic fields, which are important at all altitudes and must be considered the designs of proposed large space structures and space power systems. The status of the spacecraft charging investigations will be reviewed and the Spacecraft Active interactions will be discussed in this report.

\section{INTRODUCTION}

Very large spacecraft are being proposed for future space missions. These spacecraft are to be used for such activities as manufacturing, scientific exploration, power generation, and habitation in locations ranging from low Earth orbits (200 to $400 \mathrm{~km}$ ) to geosynchronous orbit and beyond.1-8 Structures proposed for these missions range in size from a 10 to $30 \mathrm{~m}$ Sabrication and denonstration iolcl, to a 50 to $200 \mathrm{~m}$ diameter antenna, to the several kilometer dimensions of the Solar Power Satellite (SPS).9 Because of these sizes, structures are being designed with relatively lightweight materials to achieve low densities required for transporation to space.

These spacecraft must function in the space environment. Anomalous behavior of geosynchronous satellite systems has shown that the environment is not completely benign. Interactions between the ciarged-particle environment and spacecraft exterior surfaces (i.e., spacecraft charging) can cause disruptions in spacecraft systems.10-11 The size of the new generation of spacecraft will be on the order of the ion gyro radii at geosynchronous altitudes which can increase interactions. The proposed spacecraft physical dimensions are also such that there can be real concern for the effect that the spacecraft can have on modifying the environment.

Proposed large, high power systems ranging from tenc of kilowatts 12 to gigawatts 9 have given rise to another aspect of environmental interactions. As power levels rise, operation at higher voltages is mandatory 
to reduce electrical losses while malntaining reasonable weight. in SPS design configuration calls for the generation of 10 gigawatts at $40 \mathrm{kV}$. To date, the highest operational voltage used in space is the 100-volt system on Skylab. 13 At this voltage interactions with the charged particle environment are negligible. 14 Operation at higher voltages in a plasma environment, however, can influence system performance.

To 1llustrate the types of large structures proposed for future missions, consider the system shown in figure 1.15 This system in a space construction platform with a $250-\mathrm{kW}$ power array attached to provide power for space construction operations and technology demonstrations. Note the relative size of the Shuttle orbiter compared to the struetire.

It is the interacilons of these large structures with the charged particle environment that are of concern. These interactions must be understood, evaluated, and neutralized, if necessary, in program design phases.

This report presents a review of possible interactions between spacecraft surfaces and charged-particle environments. Categories of interacical in 11 be defined and ilctí, cescribe:. The spacecraft charging investigation will be reviewed to provide insight into the large space system interactions.

\section{CATEGORIES OF SPACECRAFT-ENVIRONMENTAL INTERACTIONS}

Spacecraft-environmental inceractions can be defined as the response of spacecraft surfaces to the space charged-particle environment. These surfaces can be charged by this environment at all altitudes. However, the interactions are of concern oniy when they influence system performance.

Interactions of concern between spacecraft and environments are I1lustrated in figure 2. A pictorlal representation of a large spacecraft configuration employing a large, high-power solar array is shown. There are two broad categories of interactions indicated: Category 1, Spacecraft Passive, where the charged-particle environment acts on spacecraft surfaces and Category 2, Spacecraft Active, where the spacecraft or a system on the spacecraft causes the interaction.

The principal interaction of (.. mern in Category 1 is the spacecraft charging phenomena. Interactions in Category 2 involve the motion induced charging effects in large structures ( $1 . e_{0}$, due to spacecraft velocity) and electric field induced charging eftects in high voltage, large space power system (1.e., due to spacecraft voltages accelerating particle flows to surfaces). These interactions will be discussed in more detail in the following sections. 
Both categories of interactions are controlled by the chargedparticle flux. The net current to the conductive surfaces and to each element of insulator surface must be zero. This means that the surface voltages will be adjusted (relative to space plasma potential) until currents balance. Incoming currents and secondary, backscatter and photoemitted currents must be known in order to predict surface voltages. Coupling between various parts of the spacecraft occurs not only on the surface but also through the plasma environment complicating computations. Three dimensional analytical techniques are required to predict surface voltages even on relatively simple geometries.

\section{SPACECRAFT CHARGING INTERACTIONS}

In this section, the spacecraft charging technology investigation w111 be reviewed to emphasize the state of knowledge of interactions between spacecraft surfaces and charged-particle environments. More complete discussions can be found in the literature.10-11 A brief background on the phenomena will be given before summarizing the status.

\section{Background}

Spacecraft charging interactions occur primarily at geosynchronous altitudes when kilovolt energy particles from geomagnetic substorms electrostatically charge spacecraft surfaces. A pictorial representation of this interaction is shown in figure 3. Under normal or quiescent conditions, all satellite surfaces will be at some potential such that the net current to each surface is zero, for example, the incident electron current is equal to the sum of the incident ion, secondary emitted, backscattered and the photoemitted currents. This usually means that there w11l be a slight positive bias ( 0 to $15 \mathrm{~V})$ to restrict photoemitted currents. In substorms, the incident electron current flux is increased to $-10^{-y} \mathrm{~A} / \mathrm{cm}^{2}$ at kilovolt energy levels. This current has to be balanced and the surface potentials, relative to space plasma potential, can become strongly negative. Data from the ATS-5/6 experiments 16-17 have shown that spacecraft ground surfaces can be charged to negative kilovolt potentials under eclipse conditions (no sunlight) and

to hundreds of volts negative while in sunlight. If ground surfaces can be charged to these values, then $1 t$ is logical to assume that shadowed insulators can also be charged to large negative potentials. This gives rise to possible differential charging on parts of geosynchronous satel1ites. If this differential charging exceeds a threshold, breakdowns can occur. The resulting electromagnetic pulse from this discharge can couple into spacecraft harnesses and be interpreted by low level logic circuitry as commands causing anamolous switching events. In addition, discharges can result in deterioration of thermal control surfaces causing increased system temperatures. Differential charging can attract charged particles back to the spacecraft surfaces enhancing surface contamination. 
Both the AF and NASA personnel recognized that this environmental charging could have serious impact on the operations of long-life satellites as well as influencing scientific measurements. A joint investigation was established in 1975 to provide the design criteria, materials, techniques, and test methods which would insure control of absolute and differential charging of spacecraft surfaces. This investigation covered both ground technology and space flight experiments.

\section{Status of Charging Investigation}

In this section the status of the AF/NASA spacecraft charging investigation will be summarized by the major program elements.

Environment. - Particle data from the ATS-5 and 6 Auroral Particles Experiments have been reduced and are being compiled into an atlas. Analytical models based on these data, have been developed which characterlze the geosynchronous particle environment in terms of two-Maxwellian particle distributions and relate these distributions to the index of magnetic activity, $A_{p} .18$ The goal of such modelling efforts has been to devise statistical analytical environment models suitable for use by spacecraft designers rather than physical models of magnetospheric processes.

Analytical modelling. - A computer simulation tool called NASCAP (NASA Charging Analyzer Program) has been developed to predict timedependent charging characteristics of arbitrary shaped bodies subjected to geomagnetic substorm environments. 19 This computer code can treat simple geometries or a complete spacecraft. The equipotential profiles predicted for a teflon coated sphere subjected to sunlight and a $20 \mathrm{keV}$ substorm are shown in figure 4 (a).20 The equipotential profiles predicted for the cylindrical ATS-5 spacecraft (using teflon, quartz, and aluminum surfaces) under combined sunlight and mild substorm (5 keV) is shown in figure $4(\mathrm{~b}) .21$ Note, that in both cases, there is an asymmetric voltage distribution indicating the need for 3 dimensional treatments to isolate design areas of concern for charging-induced problems.

While charging of spacecraft surfaces can be treated reasonably well, discharge phenomena still requires more work. Breakdowns appear to originate in gaps, imperfections, or edges, 22,23 but triggering and propagation mechanisms still are unknown. These have to be understood before the treatment of breakdown in large spacecraft surfaces can be finalized.

Materials characterization. - Facilities have been developed for studying the behavior of insulators and quasi-conductors under kilovolt fluxes, 24-26 Progress has been made in understanding the factors behind the charging of these materials; it is a simple total current balance (see fig. 5). In order to compute surface potential for a given electron flux, the basic material properties of secondary yield and maximum energy, backscatter coefficlent and bulk and surface resistivities are 
required. Unfortunately, it ts not always possible to find these basic properties for ali spacectaft materials. Extrapolation of single surface results to muitiple surfaces aiso requires knowledge of the field coupling effects both on the surfaces and in space. Anaiytical modelling techniques can predict coupling and these predictions can be verified by experiments. Work in both the basic property measurements and coupling effects is underway.

Discharge phenomena studies are also being pursued.27-29 These studies have indicated that breakdown is a ccmplex process involving both positive and negative particie ejection. These experiments should lead to the development of enalytical models of the discharge phenomena.

Materials deveiopment. - Conductive pain: 30 and conductive coatings for insulatory are being developed under this element of the investigation to keep eil spacectaft extet ot surfaces neat grjund potential. Silica cloth ppears to be another materal that will not charge to appreciabie voltages in substorm condzions 32 and, hence, could be used for passive charge control. These materlals have been tested in ground sinitation facilities for charging characteristics, but only selectea conductive paints and indium oxide conductive coatings for solar cells and optical solar reflectors have been qualified for flight applications.

While conductive coatings can result in uniform exterior potentials, some projects may not want to utilize this rechnique, preferring to control discharges. This appears to be possibie by use of metallic meshes or grids. 33 Anothet possible approach to controlling discharges appears to be the use of grounded metalile frames on insulators.22,28

Space flight experiments. - The major project under this element is the AF Scatha Project (Spacecraft Charging at the High Altitudes), and is illustrated in figure 6 . This satelile will measure the synchronous environment and conduct experiments on how spacecrafe respond to this environment. The satellite will be launched early in 1979 and has a mission life of at least a year.

ATS-5 and 6 experiments have been conducted using the ion thruster neutralizers and the euroral particies experiment.17 These experiments have shown that a plasme neutxalizer (both positive and negative charges present) is an effective means of controiling spacecraft surface potentials. Thexmionis emiters (withour ascelerators) are affected by the differential tharging of 1 nsulators and emission tends to be suppressed by the presence of $10 z a \perp$ differentialiy charged insulators.

Harness noise detectors have been tlown on the Communications Technology Satellite (CTS) 35 The oceurtance of transients in spacecraft harnesses appears to be andon in iccal cime. Untortunately, there is no way to correlate these transients with the state of the environment. 
Design guidelines and test standard. - The output of the charging investigation is to be summarized in a Design Guidelines Monograph 36 and a Test Standard. 37 Preliminary versions of these documents are being issued.

\section{Discussion}

Significant progress has been made in understanding the phenomena involved in charging geosynchronous satellite surfaces by geomagnetic substorms. This investigation has emphasized the importance of knowing the basic electrical properties of the materials being used and the environment in which the system must function. Small fluxes to insulator/ conductor surfaces have resul:ed in substantial charging which can effect spacecraft system behiuist. Care and attention to decails similar to that used in high voitge technology must be exercised in order to minimize spacecraft charging anomalies.

Large space structures proposed for geosynchronous orbit add new concepts to the charging study. For these new structures, the spacecraft dimensions are larger than particle gyro radil. Particles can return to structure surfaces and influence charging interactions. Evaluation of this phenomena is not addressed in the joine AF/NASA investigation. It will be discussed in a later paper at this conference. 38

\section{LARGE SPACE SYSTEMS INTERACTIONS}

In this section interactions between charged particle environments and two classes of large space systems will be discussed. The two classes of systems are large space structures and space power systems.

\section{Large Space Structuxe Interactions}

Introduction. - The large structures envisioned for space have been described in journals and at conferences, 8 These structures range from huge to momentous. To date, designers have been more concerned with devising means of building and assembing these structures than with the effects of possible interactions with the environment. These large structures will move through the weak magnetic field around Earth and this motion will induce small electric fields. These fields can generate forces in the structure and cause particle interactions. It is the purpose of the following discussion to point out possible interactions that could influence the structure design.

Structure-environmental interactions. - Consider the pictorial representation of a large structure moving in a low Earth orbit (about $400 \mathrm{~km}$ ) across magnetic field lines as illustrated in figure $7(a)$. Th1s structure is assumed to be bulit with an open triangular truss network made from conductive materials. Across the central portion there is assumed to be a thin insulation cover. This idealized structure could be 
in reality a communications platform, an antenna system, or space power module. For convenience, it is assumed that the structure is moving perpendicular to the magnetic field and solar effects are neglected.

It is known that an electric fleld, $\vec{E}$, will be generated in a conductor moving with velocity, $\vec{v}$, in a magnetic field $(\vec{B})$ :

$$
\vec{E}=\vec{V} \times \vec{B}
$$

For the coordinate system assumed in this example the electric field will be induced in those conductors perpendicular to both the velocity and magnetic field (1.e., those conductors in the y-direction). For the velocity and magnetic field at low Earth orbit this electric field is on the order of $0.2 \mathrm{volt} / \mathrm{m} .39$ Since any surface in space must have net zero current flows and since electrons are much more mobile than lons, this electric field will be maintained such that, relative to plasma potential, the conductive surfaces will have a small area at a slight positive potential while the rest will be negatıve. A situation simllar to that shown in figure 7 (b) could exist. This is a view looking in the $x-y$ plane. The insulator surface will come to a slightly negative potential depending on 1 ts correct balance conditions and Independent of the conductive structure. Since there can be velocity effects (wake and ram induced changes in density), the voltage sheaths could be distorted as shown in the figure. The expected voltages as a function of structure dimensions for this electric fleld is shown in figure 8 . Until one starts considering multikilometer sized structures, these voltages are not too large. Since the magnet1c field diminishes with distance from Earth, these induced effects are negligible at geosynchronous altitudes.

The force or stress induced in the structure due to the electric field can be computed by means of Maxwell's stress tensor 40 as (for the simplified geometry):

$$
T=\frac{1}{2} \vec{D} \cdot \vec{E}=\frac{1}{2} \varepsilon \varepsilon_{0} E^{2}
$$

where $\varepsilon$ is dielectric constant and $\varepsilon_{0}$ is the permuttivity of space $\left(8.8 \times 10^{-12}\right.$ coulomb $^{2} /$ newton $\left.\mathrm{m}^{2}\right)$. Substituting the electric field and typical values for $\varepsilon$ results in a stress on the order of $10^{-12}$ newton $/ \mathrm{m}^{3}$. For comparison consider the forces involved in moving typical large structures from low Earth orbit to geosynchronous at the maximum $0.01 \mathrm{~g}$ acceleration desired to prevent structural damage. 41 This constraint converts into forces on the order of 100 newtons $/ \mathrm{m}^{3}$ for structures having densities similar to aluminum and of the order of $10^{-3}$ newton $/ \mathrm{m}^{3}$ for a structure 1ike the SPS module. 42 In either case the electrostatic field induced force should be too small to be of concern. 
But is this really true in all cases? Consider the thin insulator on the central portion of structure resting on the charged conductor. In space the surface of the insulator must have a net current of zero independent of the structure. Hence, the insulator surface could be close to zero volts. Therefore, there will be a differential voltage across the insulator and hence, an electric field through the insulator. This electric field can result in significant stress in the insulator. For example, a $2 \mathrm{mil}(0.005 \mathrm{~cm})$ thick insulator with a differential voltage of 20 volts will have a stress induced on the order of 0.2 newton $/ \mathrm{m}^{3}$. This is not a negligibly small stress. The results of a computation of the stress induced on a 2-mi1-thick insulator as a result of various differential voltages is shown in figure 9.

Discussion. - The above computations have indicated that fairly large stresses can be induced in thin insulator (dielectric) surfaces by relatively small differential voltages anticipated for large structures. These computations are admittedly simplistic and have neglected several interactions that could either worsen or alleviate the stresses. The exercise is meant only to illustrate an effect that may exist and to point out that care must be used in judging which effects should be incorporated and which ignored.

A much more detailed analysis is required before any definite conclusions can be reached on the induced stresses. Even if this more complete analysis shows that relatively large stresses do exist, then these stresses can be compensated for in the design phases. With reasonable examination of the areas where insulators, conductors, and space come together, interaction effects can be minimized and large structures built for space applications.

\section{Space Power System Interactions}

Introduction. - One class of large structures envisioned for future missions are space power systems utilizing solar arrays. A 25-kilowatt system has been proposed to supplement the Shuttle orbiter power capabilities. 12 Future plans call for systems with power generating capabilities of up to 500 kilowatts to be launched in the late eighties and early nineties 16 When the power levels rise, operating voltages must increase above the 30 to 100 volt levels presently used in order to improve efficiency and reduce weight. It is the electric fields generated by higher operating voltages of these power systems that cause interactions with the space plasmas. This interaction has been studied in ground simulation facilities $43-46$ and a space flight experiment. 47 Results of these studies can be used to understand the reactions involved in this phenomena.

High voltage surface-plasma interactions. - This interaction is illustrated in figure 10 which shows a solar array system in a space environment. In the standard construction of this array, cover slides 
do not completely cover the metallic interconnects between the solar cells. These cell interconnects are at various voltages depending on their 10cation in the array circuits. Because the array is exposed to space plasmas, the interconnects act as biased plasma probes attracting or repelling charged particles. At some location on the array the generated voltage is equal to space plasma potential. Cell interconnects that are at voltages $\left(V_{+}\right)$above the space potential will attract an electron current which depends upon electron density and energy as well as the voltage difference between the interconnect and space. Those interconnects that are at voltages $\left(V_{-}\right)$below space plasma potentials w1ll repel electrons and attract an ion current. The voltage distribution in the interconnects relative to space potential, must be such that electron and ion currents are equal. This flow of particles can be considered a current loop through the power system to space. It is a parallel electrical load with the power system and, as such, represents an additional power loss. One would expect this interaction to be more pronounced at low Earth orbits because of the high number density of low energy plasma (see fig. II).

Ground simulation tests of biased solar array segments have shown the behavior of these systems when exposed to plasma environments. A small segment consisting of twenty-four $2 \times 2 \mathrm{~cm}$ cells connected in series (area $-100 \mathrm{~cm}^{2}$ ) mounted on a fiberglass board has been tested. $45 \mathrm{~A}$ thermal plasma environment with densities of $\sim 10^{3}\left(\mathrm{~cm}^{-3}\right)$ and $\sim 10^{4}\left(\mathrm{~cm}^{-3}\right)$ and energies of about $1 \mathrm{eV}$ was generated in the vacuum tank. The solar cell clrcult on the array was biased by laboratory power supplies in both positive and negative voltage steps from 0 to \pm 1000 volts, relative to tank ground. The plasma coupling current (through the environment) and the voltage profile across the solar array surface was measured at each voltage step. These results are shown in figures $12(a)$ and (b). The voltage profiles were similar for both plasma density tests and only one set has been reproduced.

When low positive bias voltages $(\leq 100 \mathrm{~V})$ were applied to the segment, the quartz cover slides acquired a slight negative potential to maintain equal electron and fon currents to that surface. This negative surface voltage appears to suppress the electric field expansion into the plasma at the interconnects to values less than 10 percent of the applied voltage. The surface voltage measurements were taken 3 mn above the quartz surface with a capacitively-coupled voltmeter. The plasma coupling current also showed the effect of this voltage suppression; in this voltage regime, the current collection is proportional to the smaller voltage, not the applied voltage.

As the positive bias voltage was increased, there was a transition in the surface voltage profiles: surface voltage sheaths had apparently "snapped-over" or expanded to encompass the cover slides. A voltage sheath is the distance required for the voltage to decay to plasma potential 
due to the rearrangement of plasma particles. Snap-over seemed to occur when the sheath approached solar cell dimensions. Effective surface voltage after snap-over was about 50 volts less than the applied voltage. The plasma coupling current also indicated this transition at about 100 volts (see f1g. 12(a)). Above applied positive voltages of 100 volts, the current collection was proportional to the panel area and the 0.8 power of the effective voltage.

When negative bias voltages were applied to the solar cell segment, the quartz cover slides again assumed a slightly negative voltage $(\sim-2$ to $-2 \mathrm{~V})$ suppressing the fields at the interconnects (see fig. $12(b))$. Instead of a snap-over phenomenon, confinement of interconnect electric fields persisted until the field built up to a point where discharges occur. The voltage at which breakdown occurred appeared to be plasma density dependent. For the tests considered here, breakdown occurred at about -600 volts at densities of $-10^{4} \mathrm{~cm}^{-3}$ and about -750 volts at densities of $-10^{3} \mathrm{~cm}^{-3}$. The plasma coupling currents also indicated the transitions to arcing.

These characteristics observed in the laboratory have been verifled in space with an auxiliary payload package called PIX (Plasma Interaction Experiment).47 This package was carried on the Delta second stage during the Landsat III launch, March 5, 1978 and operated in a 900-km polar orbit for 4 hours. Only the plasma coupling currents were measured as a function of voltage but the comparison to the laboratory test data was excellent (see fig. 13).

In order to extend these laboratory results to space power system interactions, one must know the floating potential of the array relative to space. This is a complex computation, but if one makes the approximation that the array will be no more than 10 percent positive $\left(V_{+}\right)$and 90 percent negative $\left(V_{-}\right)$, then the effect of the plasma interactions can be estimated. This split in voltage is probably conservative and the array will float at only a few percent positive. The system operating voltage will be the sum of the absolute values of the floating potentials (1.e., $\left.V_{L}=\left(V_{+}\right)+\left(V_{-}\right)\right)$. Using the above split in voltages and the laboratory derived characteristics, the ratio of the plasma coupling current to the operating current is shown in figure 14 as a function of operating voltage. This curve is typical for any power level in a $400-\mathrm{km}$ orbit.

It is apparent that plasma coupling currents are negligibly small at operating voltages less than 500 volts and power systems operating at this voltage are feasible from an environmental interation viewpoint. The limltation in operations at higher voltages appears to be arcing in the negative portions of the array. If this arcing is truly an electric field confemenent effect, then a technology investigation should lead to pratical methods of overcoming this limltation. 
Extrapolating these results to geosynchronous orbits indicates that coupling current losses should be even less of a concern. However, the arcing problem does exist. Laboratory data has shown that arcing could occur when operating voltages exceed 5000 volts.

Discussion. - Laboratory data has indicated that high voltage systems in space if used must be carefully engineered. There can be interactions between the space charged-particle environment and the biased conductors surrounded by insulator surfaces. While the anticipated plasma coupling current power loss probably will be negligible, a breakdown condition exists which unless it could be overcome would limit operating voltages.

The above comments are based on what were essentially short time experiments. The space power systems have been proposed for multiyear operation (up to $30 \mathrm{yr}$ for the SPS). Therefore, long time effects must be evaluated for high voltage system - space plasma interactions. Such 1tems as the effect of long time deposition of charges in and on insulator surfaces and the influence of electrostatically enhanced contamination must be assessed before these high voltage systems can safely and rellably function in space.

\section{CONCLUDING REMARKS}

Some future space missions have requirements which cannot be satisfied by present day spacecraft and are proposing the orbiting of very large deployable or erectable structures. These new spacecraft will have dimensions ranging up to kilometers and will use lightweight materials to achieve the required low density. These proposed new spacecraft must function in a charged-particle space environment which means that the possible interactions between this environment and spacecraft surfaces must be identified and evaluated.

Two broad categories of spacecraft surface-charged particle environmental interactions have been identified: Spacecraft Passive, when the environment acts on the spacecraft and Spacecraft Active, when a spacecraft system causes the interaction. The principal interaction in the first category is the spacecraft charging phenomena. The investigation of this interaction started 3 years ago and much has been accomplished. The results of the investigation, to date, have pointed out the need to exerc1se care in designing spacecraft since environmental fluxes can influence spacecraft system performance. In addition the spacecraft charging impact on very large spacecraft proposed for future mission has not yet been considered, but must be evaluated.

The second category of interactions involves motion induced effects on large structures and the use of on-board high voltage systems. There are indications that spacecraft motion through the Earth's magnetic field can induce additional and significant stresses in insulator-conductor 
interfaces. These stresses must be assessed and relieved in large structure designs. The use of high voltage system in space requires similar care as ground applications of high voltage systems. In both cases, breakdowns are possible unless reasonable design guidelines are used. Both types of interactions considered here are more serious at low-Earth orbits compared to geosynchronous orbits.

All interactions discussed here involve the requirement that the net currents to surfaces be zero. This applies to conductors as well as insulators. In space, surface voltages will automatically adjust so that this requirement will be satisfied. Electric flelds from these charged surfaces will interact in the plasma environment influencing particle fluxes. It is the goal of the technology investigations to understand these complex interactions and to devise means to minimize their effects on spacecraft system performance.

\section{REFERENCES}

1. "Outlook for Space," NASA SP 386, Jan. 1976.

2. Johnson, R. D., and Holbrow, C., eds., "Space Settlements, A Design Study," NASA SP 413, 1977.

3. Woodcock, G. R., Solar Satellites, Space Key to Our Future," Astronautics and Aeronautics, Vol. 15, July/Aug. 1977, pp. 30-43.

4. "Satellite Power System (SPS) Feasibility Study," Rockwell International Corp., Downey, Calif., SD76-SA-0239-1, 1976. (NASA-CR150439.)

5. "Systems Definition of Space-Based Power Conversion Systems," Boeing Aerospace Co., Seattle, Wash., D180-20309-1, 1977. (NASA(R-150209.)

6. Poeschel, R. L., and Hawthorne, E. I., "Extended Performance Solar Electric Propulsion Thrust System Study, Vol. 2, Baseline Thrust System," Hughes Research Labs., Malibu, Calif., 1977. (NASA (R-135281.)

7. Friedman, L. D., et al., "Solar Sailing - The Concept Made Realistic," AIAA Paper 78-82, Jan. 1978.

8. For example see papers in AIAA Conference on Large Space Platforms: Future Needs and Capabilities, Los Angeles, Calif., Sep. 27-29, 1978.

9. Nansen, R. H., "Solar Power Satellite: Can We Afford to Ignore It?" Paper presented at AIAA Conference on Large Space Platforms. Future Needs and Capabilities, Los Angeles, Calif., Sep. 27-29, 1978. 
This Page Intentionally Left Blank 
21. Roche, J. C., and Purvis, C. K., "Comparison of NASCAP Predictions with Experimental Data," Presented at the 2nd USAF/NASA Spacecraft Charging Technology Conference, US Air Force Academy, Colorado Springs, Colo., Oct. 31-Nov. 2, 1978, Session II-3.

22. Stevens, N. J., Purvis, C. K., and Staskus, J. V., "Insulator Edge Voltage Gradient Effects in Spacecraft Charging Phenomena," Presented at the 1978 IEEE Annual Conference on Nuclear and Space Radiation Effects, Albuquerque, N. Mex., July 18-21, 1978, Session C-3.

23. Aron, P. R., and Staskus, J. V., "Area Scaling Investigations of Charging Phenomenon," Presented at the 2nd USAF/NASA Spacecraft Charging Technology Conference, US Alr Force Academy, Colorado Springs, Colo., Oct, 31-Nov。 2, 1978, Session IV-3.

24. Berkopec, F. D., Stevens, N. J., and Sturman, J. C., "The LeRC Geomagnetic Substorm Simulation Facility," in Proceedings of the Spacecraft Charging Technology Conference, C. P. Pike and R. R. Love11, eds., Air Force Geophysics Lab., AFGL-TR-77-0051 and NASA TM X-73537, Feb. 1977, pP. 423-430。

25. Saylor, W., "Electrical Equilibrium of Dielectrics When Exposed to Energetic Electron Beams," in Proceedings of the Spacecraft Charging Technology Conference, C. P. Pike and R. R. Lovell, eds., Air Force Geophysics Lab., AFGL-TR-77-0051 and NASA TM X-73537, Feb. 1977, pp. 517-518.

26. Reddy, J., and Serene, B. E., "Effects of Electron Irradiation on Large Insulating Surfaces Used for European Communications Satellites," Presented at the 2nd USAF/NASA Spacecraft Chargine Technology Conference, U.S. Air Force Academy, Colorado Springs, Colo., Oct. 31-Nov. 3, 1978, Session IV-7.

27. Adamo, R. C., and Nanevicz, J. E., "Spacecraft Charging Studies of Voltage Breakdown Processes on Spacecraft Thermal Control Mirrors," in Spacecraft Charging by Magnetospheric Plasmas, Progress in Astronautics and Aeronautics, Vo1. 47, A. Rosen, ed., New York, AIAA, 1976, pp. 224-235.

28. Yadlowsky, E. J., Hazelton, R. C., and Churchill, R. J., "Puncture Discharges in Surface Dielectrics as Contaminant Sources in Spacecraft Environments," Colorado State University, Fort Collins, Colo., 1978. (NASA-CR-157105.)

29. Balmain, K. G., "Scaling Laws and Edge Effects for Polymer Surface Discharges," Presented at the 2nd USAF/NASA Spacecraft Charging Technology Conference, US Air Force Academy, Colorado Springs, Colo., Oct. 31-Nov. 2, 1978, Session V-3. 
30. Gilligan, J. E, Yamauch1, I。, Wolf, R。E., and Ray, C., "Electrically Conductive Paints for Sateliztes," Air Force Materials Lab., AFML-TR-76-232, Dec. 1976. (AD-B019633L.)

31. Schmidt, R. E., and Eagles, A. E., "Materials and Techniques for Spacecraft Static Charge Control II," Presented at the 2nd USAF/ NASA Spacecraft Charging Technology Conference, US Air Force Academy, Colorado Springs, Colo., Oct. 31-Nov. 2, 1978, session IV-4.

32. Belanger, V. J., and Eagles, A. E., "Secondary Emission Conductivity of High Purity Silica Fabric," in Proceedings of the Spacecraft Charging Technology Conference, C. P. Pike and R. R. Lovell, eds., Air Force Geophysies Lab。, AFGL-TR-0051 and NASA TM X-73537, Feb. 1977, pp.655- 068 。

33. Robinson, P. A., Jr., "The Bahavior of Partially Metallized Kapton," AIAA Paper 78-675, Apr。 1978.

34. Durrett, J. C., and Stevens, J。 R., "Space Test Program P78-2 Space Flight Overview," Presented at the 2nd USAF/NASA Spacecraft Charging Technology Conference, US Alr Force Academy, Colorado Springs, Colo., Oct. 31-Nov, 1978.

35. Stevens, N. J., Klinect, V. W., and Gore, J. V., "Summary of the CIS Transient Event Counter Data After One Year of Operation," IEEE Transactions, Nuclear Science, Vol. NS-24, Dec. 1977, pp. 22702275.

36. Kamen, R. E., Holman, A. B., Stevens, N, Jo, and Berkopec, F. D., "Design Guidelines for Control of Spacecraft Charging," Presented at the 2nd USAFiNASA Spacecraft Charging Technology Conference, US Air Force Academy, Colorado Springs, Colo, Oct. 31-Nov. 2, 1978, Session VI-5.

37. Holman, A。B。, and Bunn, M., "Spacecraft Charging Standard Development," Presented at the 2nd USAF/NASA Spacecraft Charging Technology Conference, US Air Force Academy, Colorado Springs, Colo., Oct. 31-Nov. 2, 1978, Session VI-3.

38. DeForest, S., "Spacecraft Charging and Related Effects on Space Structures," AIAA Paper 79-0389, Jan. 1979.

39. Whipple, E. C., Jr., "The Equilibrium Electric Potential of a Body in the Upper Atmosphere and in Interplanetaxy Space," NASA TM $\mathrm{X}-55368,1965$.

40. Panofsky, W. K. $H_{c}$, and Phillips, $M_{c}$, Classical Electricity and Magnetism, Addison-Wesley, Reading, Mass., 1955. 
41. Terwilliger, C. H., "Electric Propulsion for Near-Earth Space Missions," Boeing Aerospace Co., Seattle, Wash., D180-24819-1, Oct. 1978.

42. "Solar Power Satellite-System Definftion Study, Parts 1 and 2, Vo1. 2: Technical Summary," Boeing Aerospace Co., Seattle, Wash., D180-22876-2, Pts. 1 and 2, Vol. 2, 1977. (NASA-CR-151666.)

43. Kennerud, K. L., "High Voltage Solar Array Experiments," Boeing Aerospace Co., Seattle, Wash., 1974. (NASA-CR-121280.)

44. Stevens, N. J., "Solar Array Experiments on the SPHINX Satellite," NASA TM X-71458, 1973.

45. Stevens, N. J., Berkopec, F. D., Purvis, C. K., Grier, N. T., and Staskus, J. V., "Investigation of High Voltage Spacecraft System Interactions with Plasma Environments," AIAA Paper 78-672, Apr. 1978.

46. McCoy, J. E., and Konrad1, A., "Sheath Effects Observed on a 10-Meter High Voltage Panel in Simulated Low Earth Orbit Plasmas," Presented at the 2nd USAF/NASA Spacecraft Charging Technology Conference, US Air Force Academy, Colorado Springs, Colo., Oct. 31-Nov. 2, 1978, Session III-3.

47. Grier, N. T., and Stevens, N. J., "Plasma Interaction Experiment (PIX) Satellite Results," Presented at the 2nd USAF/NASA Spacecraft Charging Technology Conference, US Air Force Academy, Colorado Springs, Colo., Oct. 31-Nov. 2, 1978, Session III-2. 


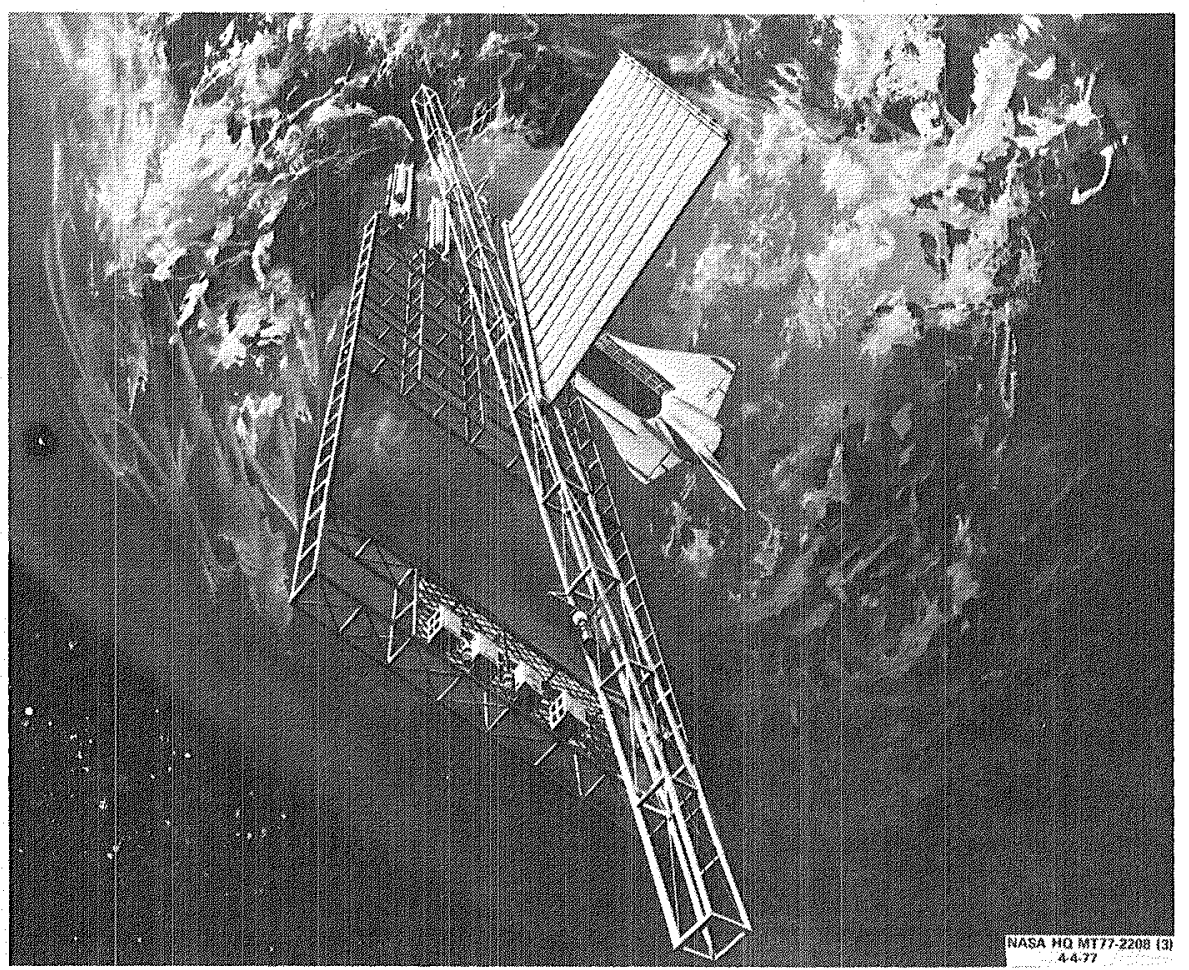

Figure 1. - Space Construction Facility (ref。16).

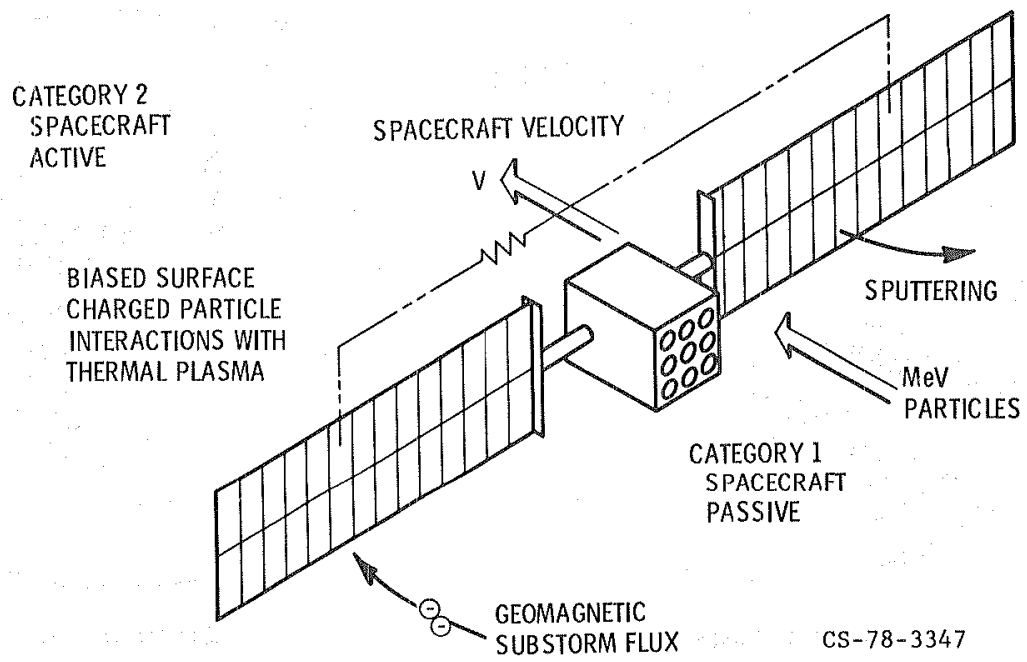

Figure 2. - Spacecraft-environment interactions. 


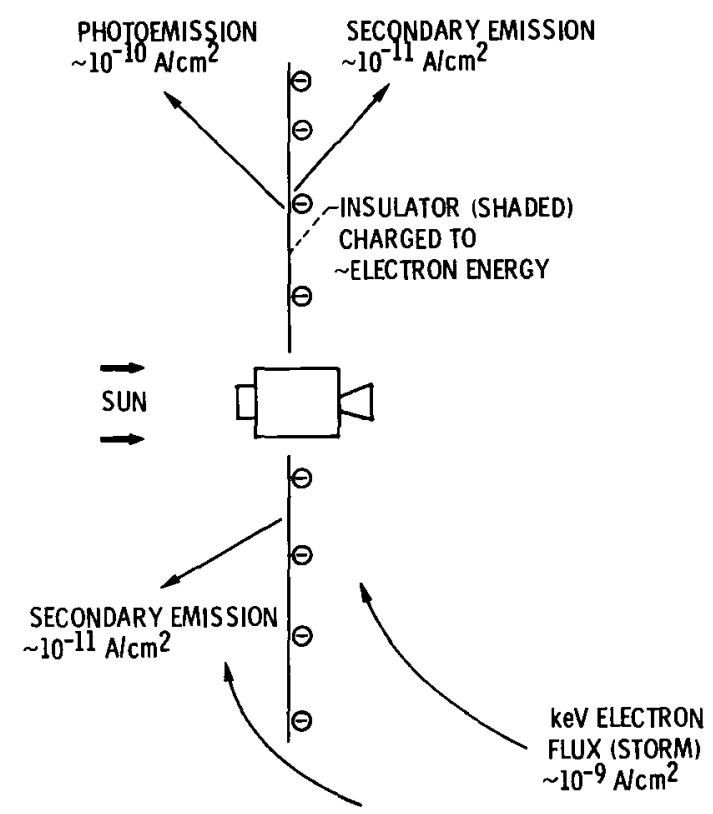

Figure 3 - Spacecraft charging interactions

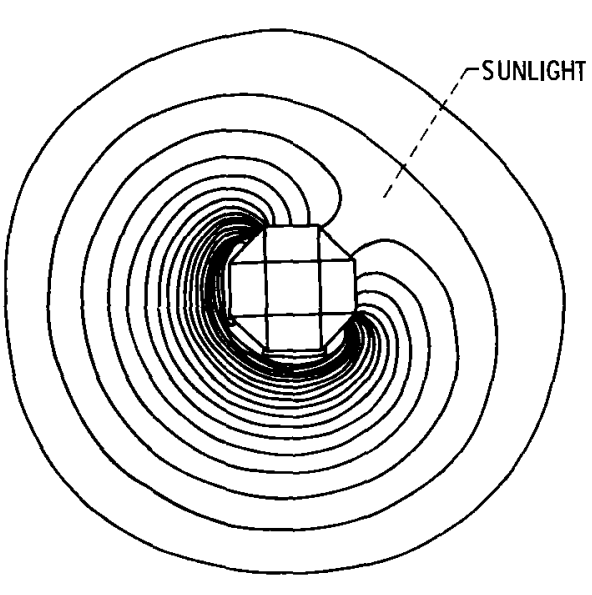

(a) TEFLON SPHERE

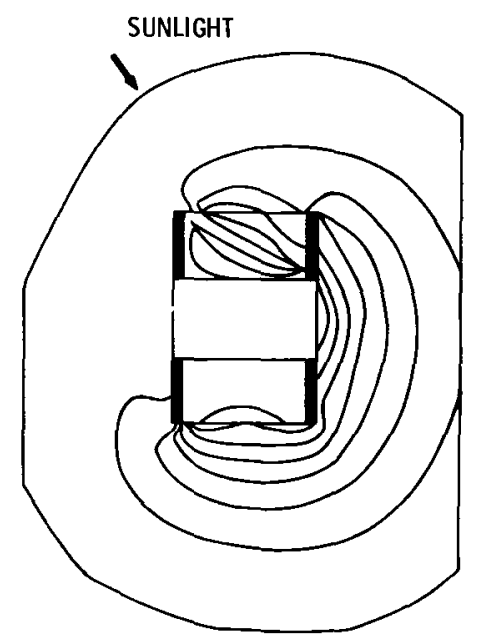

(b) ATS-5 SATELLITE MODEL

Figure 4 - NASCAP potential distribution predictions 


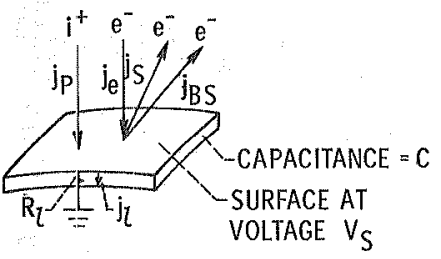

\section{ASSUMPTIONS}

GEOMAGNETIC SUBSTORM

ISOTROPIC MAXWELLIAN DISTRIBUTIONS

SPHERICAL COLLECTION GEOMETRY

CHARGING MODEL

$$
-j_{e}\left(V_{S}\right)+j_{p}\left(V_{S}\right)+j_{S}\left(V_{S}\right)+j_{B S}\left(V_{S}\right)=j_{l}\left(N_{S}\right)+j_{C}\left(V_{S}, t\right)
$$

FUNCTIONAL FORMS

DARK CONDITION $\rightarrow$ NO PHOTOEMISSION

\section{SYMBOL \& FORMULA}

$$
\begin{aligned}
& j_{e}=j_{e 0} \exp \left(\frac{V_{S}}{V_{e}}\right) \\
& j_{p}=j_{p O}\left(1-\frac{V_{S}}{V_{p}}\right) \\
& j_{s}=j_{e 0} \sqrt{\pi} 7.4 \delta_{m} \frac{V_{e}}{V_{m}} 5 !\left[i_{e r f c}\left(\sqrt{\frac{V_{e}}{V_{m}}}\right)\right] \exp \left(\frac{V_{e}}{V_{m}}+\frac{V_{s}}{V_{e}}\right) \\
& \mathrm{j}_{\mathrm{BS}}=\mathrm{j}_{\mathrm{eO}} \exp \left(\frac{V_{S}}{V_{e}}\right) \\
& j_{l}=\frac{V_{S}}{R_{l}}=\frac{V_{S}}{\rho l} \\
& \mathrm{j}_{\mathrm{C}}=\mathrm{C} \frac{\mathrm{dV_{S }}}{\mathrm{dt}}
\end{aligned}
$$

CURRENT DENSITY DUE TO

\section{PLASMA ELECTRONS}

(where $V_{e}$ is electron temperature in volts)

PLASMA IONS

(where $V_{p}$ is proton temperature in volts)

SECONDARY ELECTRONS

(with max yield, $\delta_{m}$, at energy $V_{m}$ )

BACKSCATTERED ELECTRONS

(where $\zeta$ is backscatter coefficient)

LEAKAGE THROUGH INSULATOR

SURFACE CHARGING CS-78305

Figure 5. - 1-D model space substorm environment.

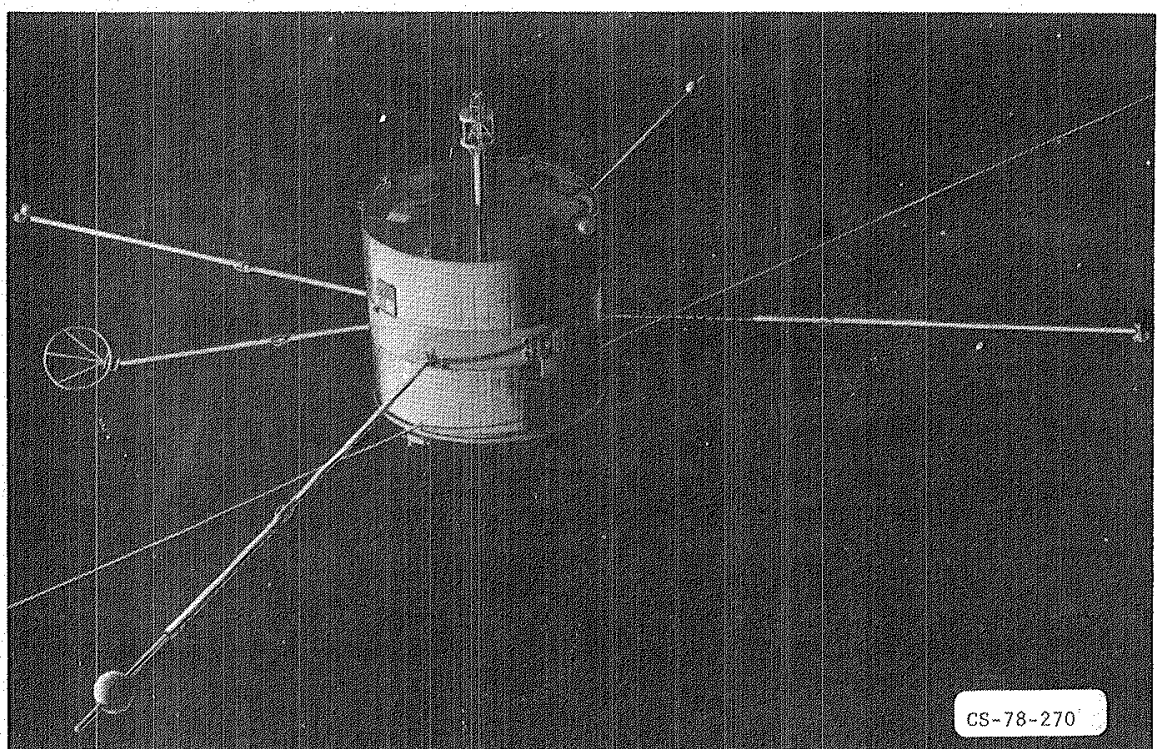

Figure 6. - Scatha Satelite. 

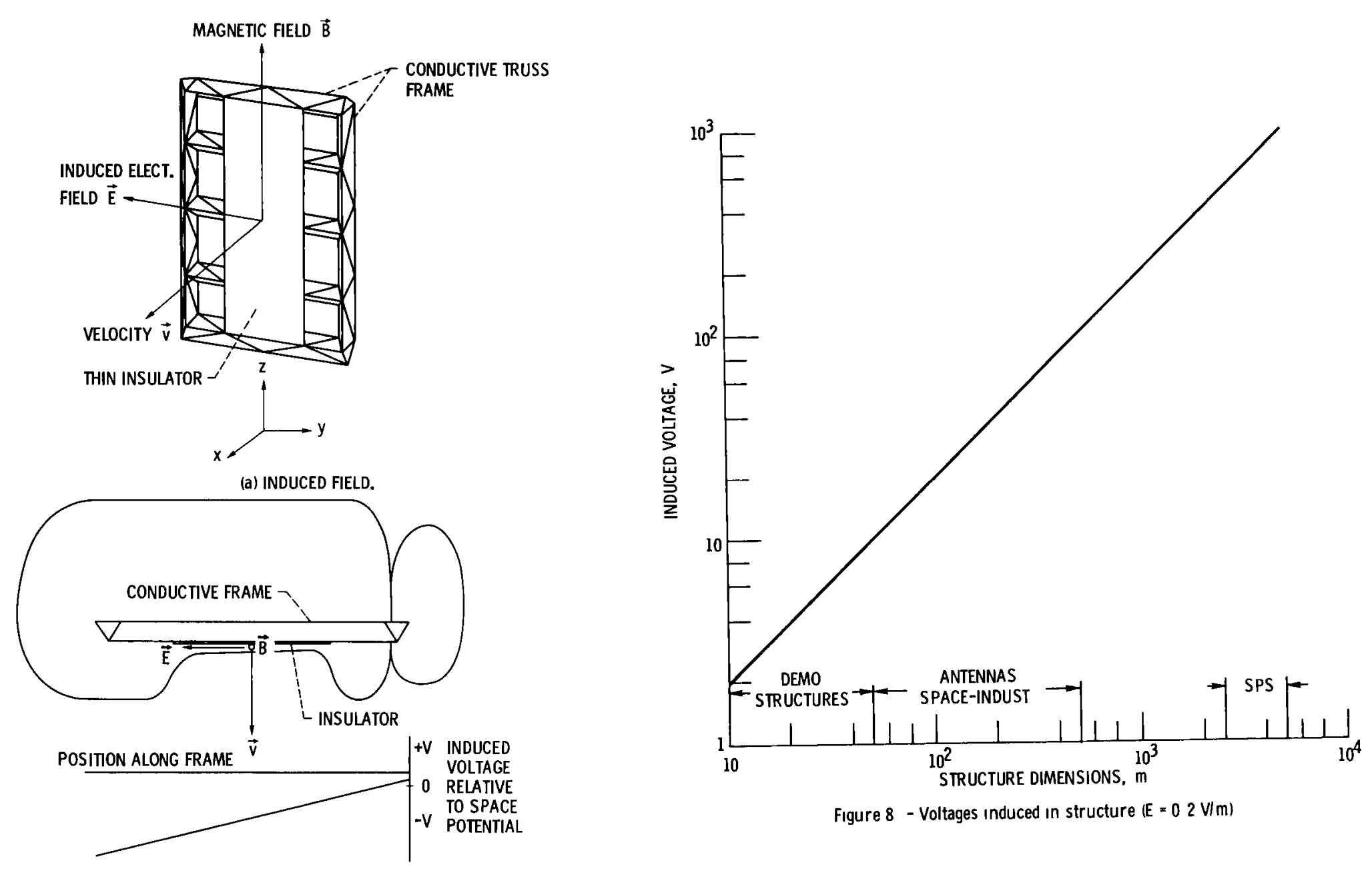

(b) POSSIBLE VOLTAGE SHEATHS.

Figure 7 - Large space structure Interaction 


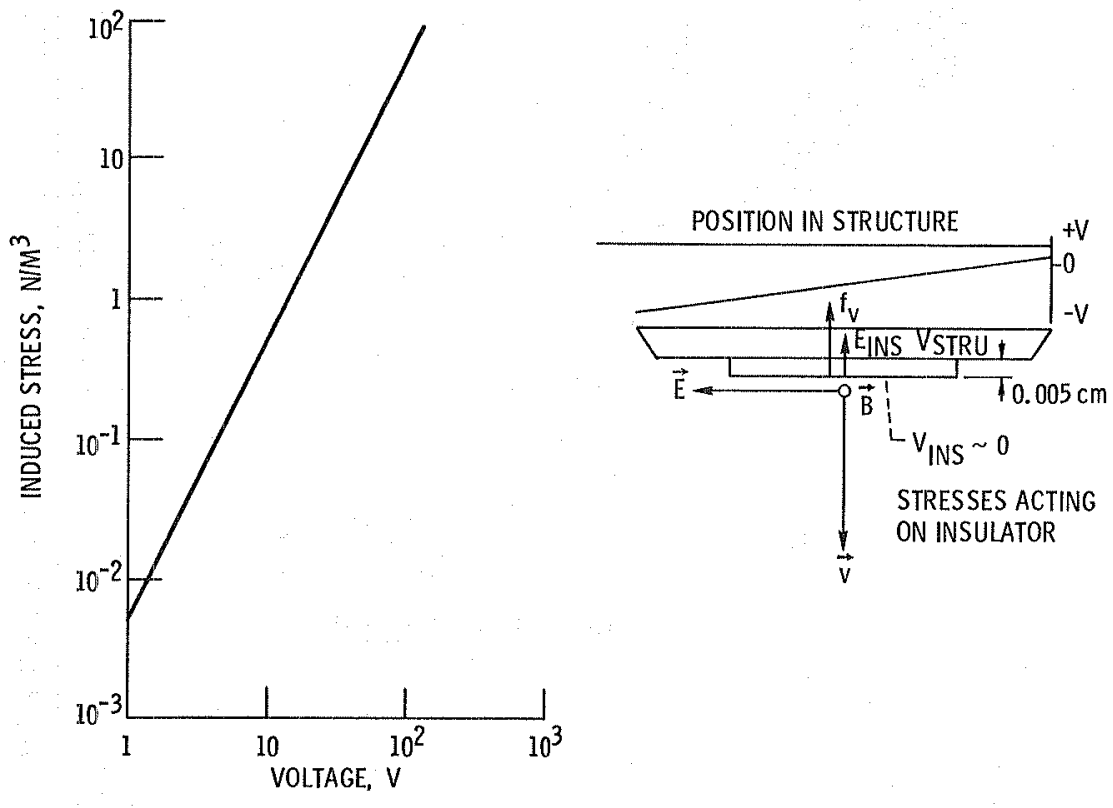

Figure 9. - Stress induced in $0.005 \mathrm{~cm}$ insulator by voltage across insulator.

10
0
0
1
1

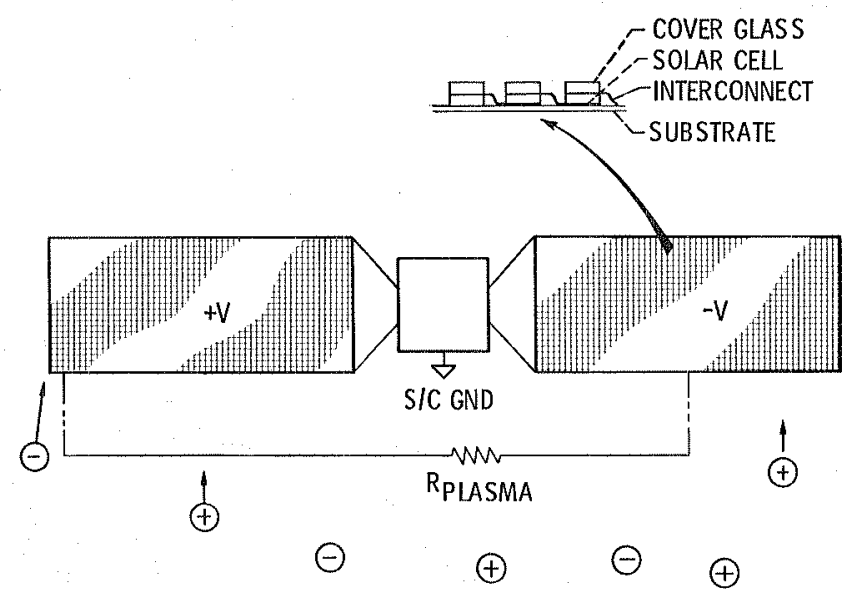

Figure 10. - Spacecraft higher voltage system-environment interactions. 


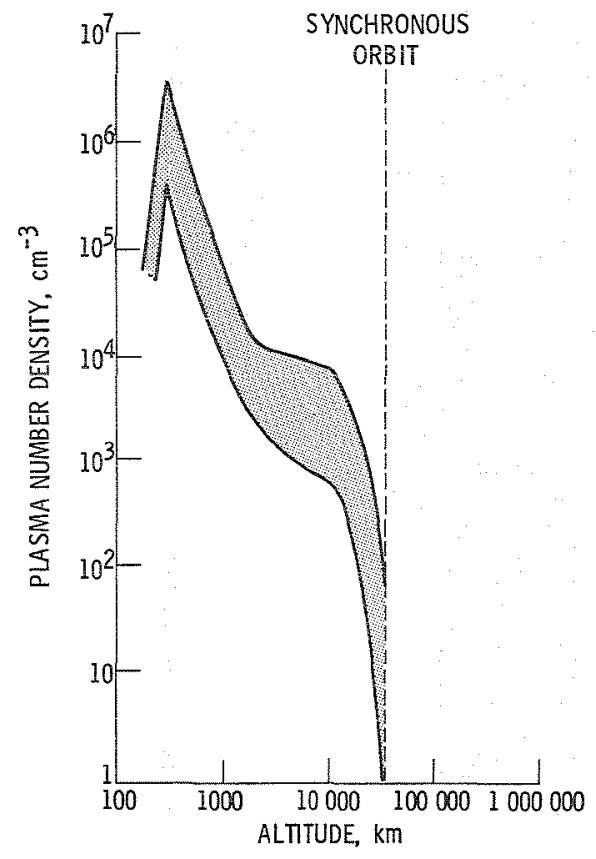

Figure 11. - Plasma number density vs altitude in equatorial orbit (ref. 32).
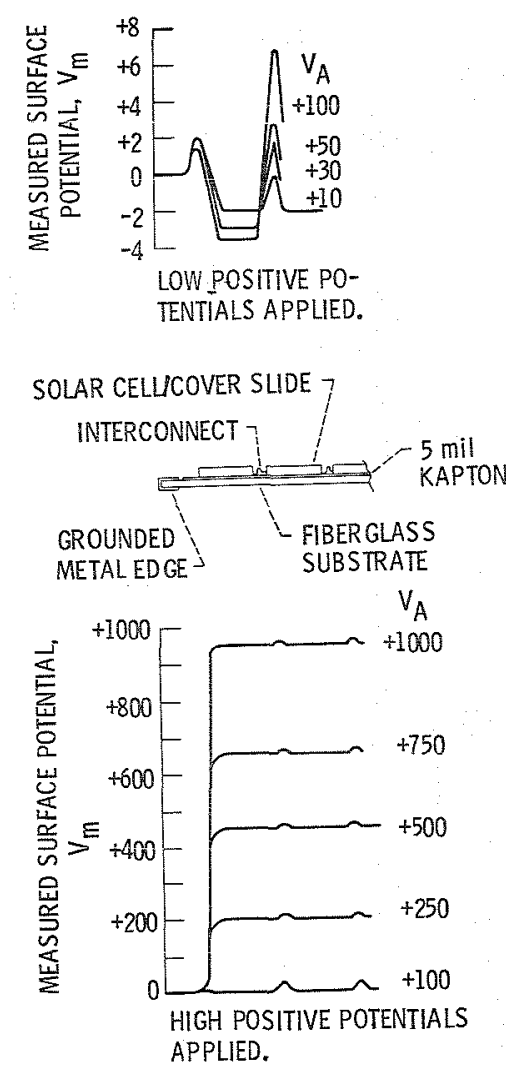

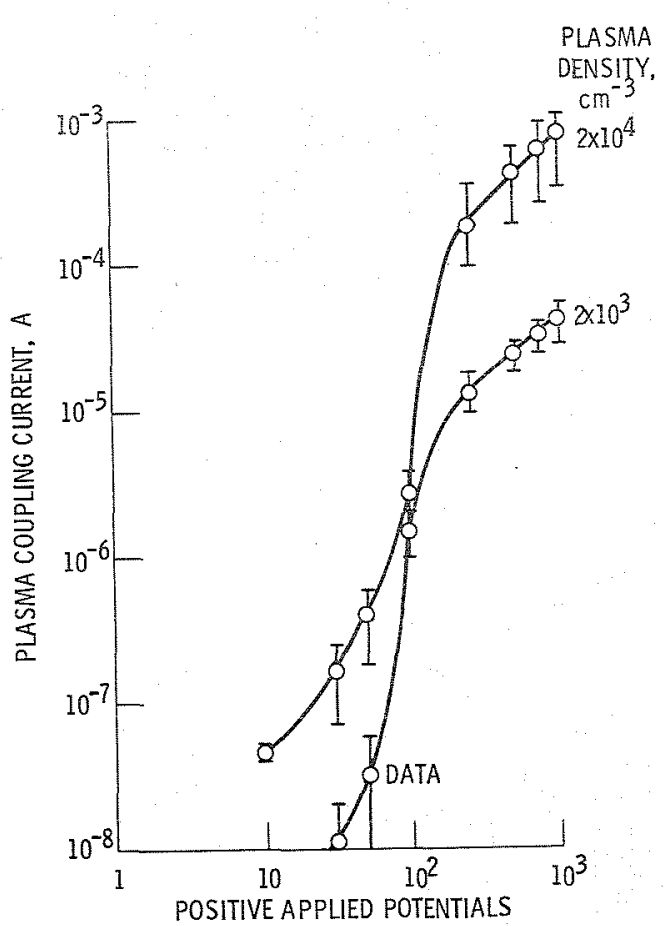

(a) POSITIVE APPLIED POTENTIALS.

Figure 12. - Solar array surface voltage profiles and coupling currents. 
LOW NEGATIVE POTENTIALS APPLIED.

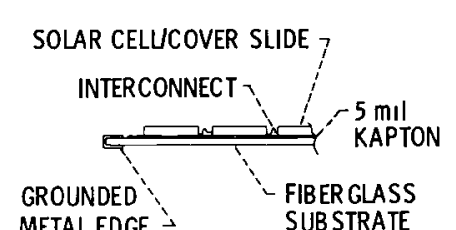
METAL EDGE - SUB STRATE
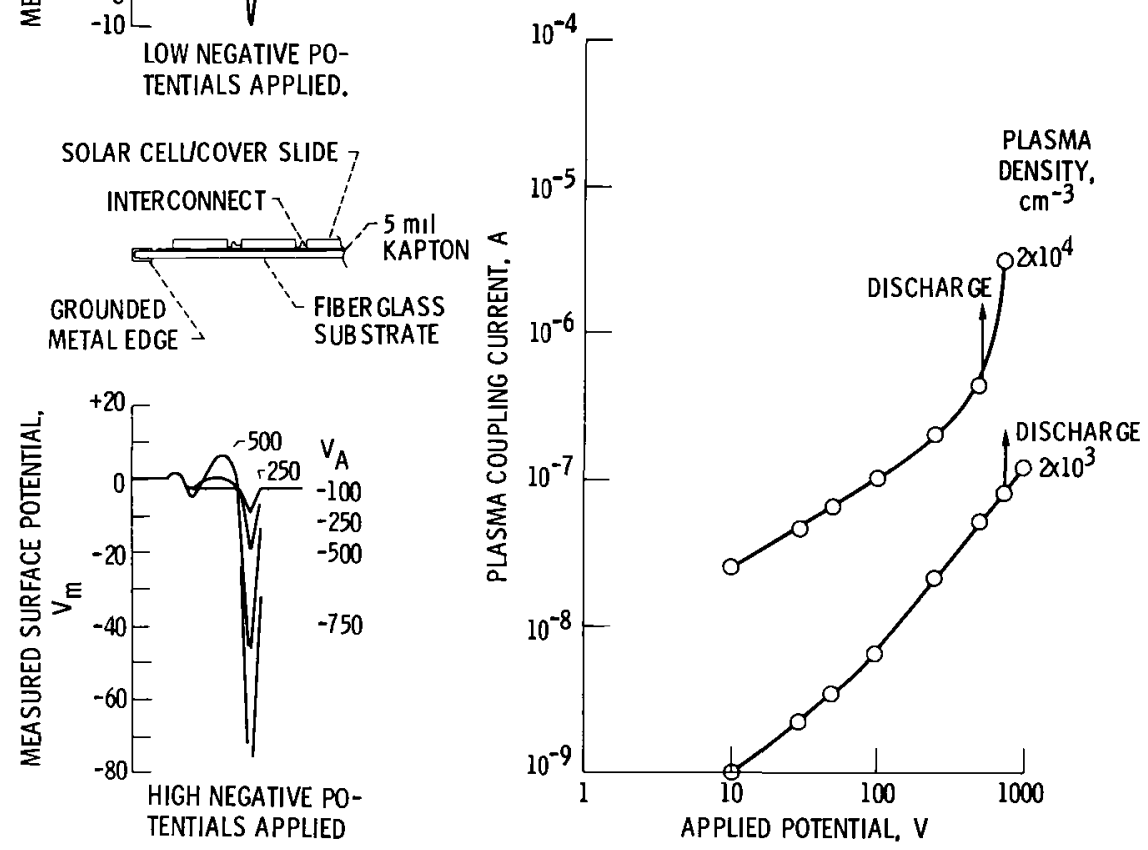

(b) NEGATIVE APPLIED POTENTIALS

Figure 12 - Concluded 

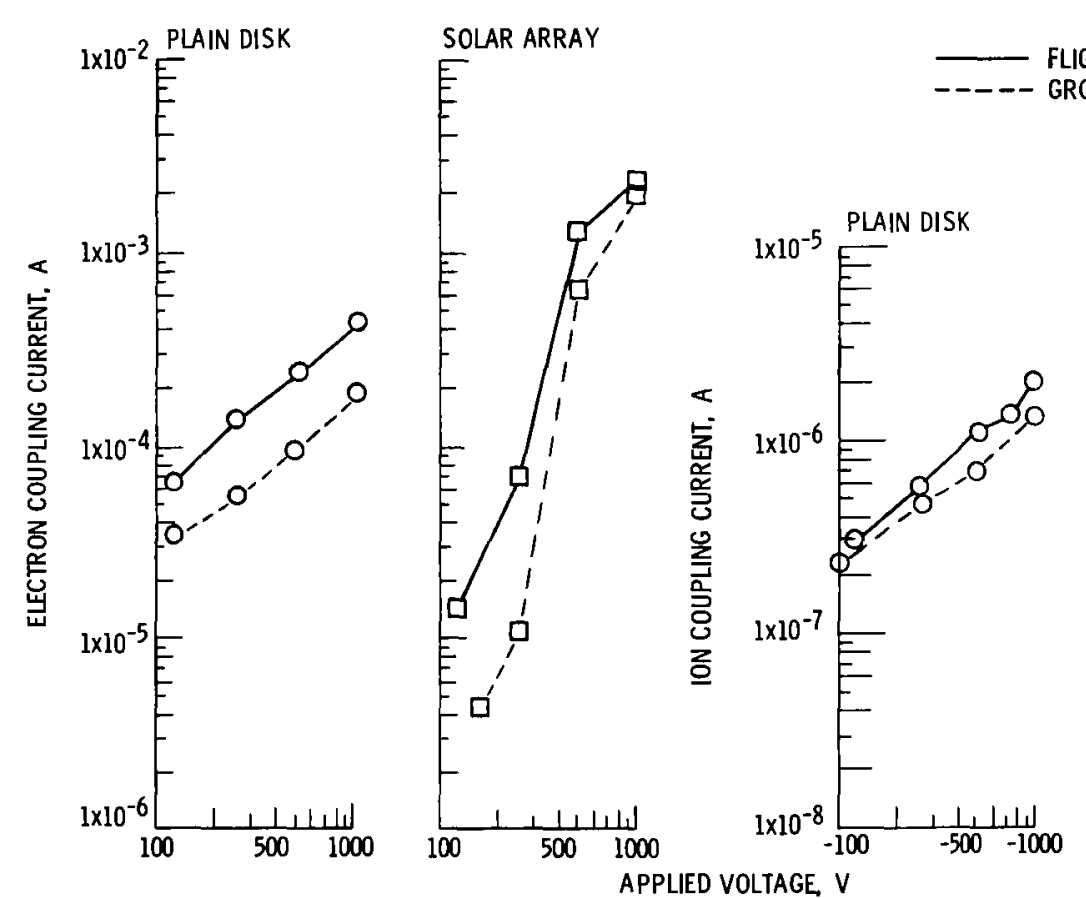

DATA

GOUND TEST RESULTS

(a) POSITIVE APPLIED VOLTAGES

\section{(b) NEGATIVE APPLIED VOLTAGES}

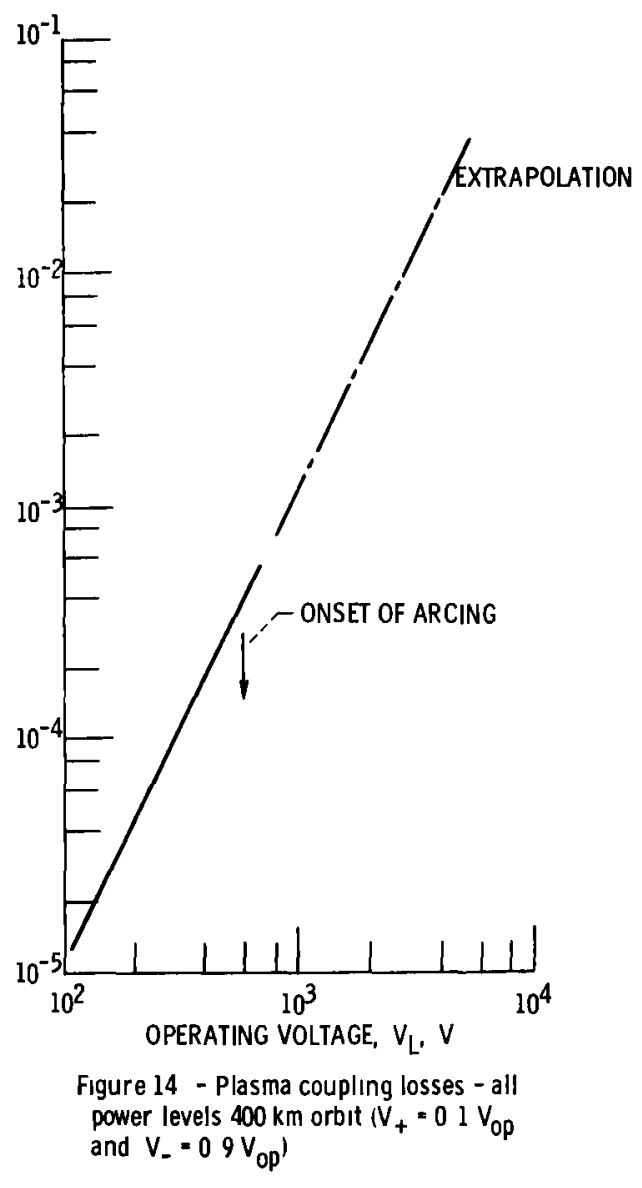


End of Document 